\title{
Is chronic low back pain and radicular neuropathic pain associated with smoking and a higher nicotine dependence? A cross-sectional study using the DN4 and the Fagerström test for nicotine dependence
}

\author{
Kronik bel ağrısı ve radiküler nöropatik ağrı, sigara içme ve daha yüksek nikotin bağımlılığı ile \\ ilişkili midir? Nikotin bağımlılı̆ı için DN4 ve Fagerström testinin kullanıldığı kesitsel bir çalısma
}

(1) Emanuel SCHEMBRI, ${ }^{1}$ (1) Victoria MASSALHA, ${ }^{2}$ @ Liberato CAMILLERI, ${ }^{3}$ (I) Stephen LUNGARO-MIFSUD ${ }^{4}$

\begin{abstract}
Summary
Objectives: To evaluate, if a current smoking status and a higher nicotine dependence were associated with chronic low back pain (LBP) and/or radicular neuropathic leg pain.

Methods: The study was designed as a cross-sectional study on the first eligible consecutive 120 patients. Demographic data, pain intensity, worst pain location, most distal pain radiation, the DN4 questionnaire, STarT back tool, and the Fagerström test were collected during the initial examination. An age- and gender-matched control group $(n=50)$, free from chronic LBP was recruited.

Results: In the chronic pain group, there was a significant difference between smokers and lifetime non-smokers in the average pain intensity score $(p=0.037)$, total DN4 score $(p=0.002)$, STarT Back tool $(p=0.006)$, worst pain location $(p=0.023)$, and the most distal pain radiation $(p=0.049)$. The mean total DN4 score increased with a corresponding increase in the number of cigarettes smoked daily $(p=0.002)$. Current smokers had an OR of $3.071(p=0.013)(95 \% \mathrm{Cl} 1.268-7.438)$ for developing chronic LBP and lumbar related leg pain and an OR of $6.484(p<0.001)(95 \% \mathrm{Cl} 2.323-18.099)$ for developing chronic radicular neuropathic leg pain. For every one-unit increase in the Fagerström test score, the likelihood for chronic LBP and lumbar related leg pain increased by $40.71 \%(p=0.008)(95 \%$ $\mathrm{Cl} 1.095-1.809)$ and for chronic radicular neuropathic leg pain increased by $71.3 \%(\mathrm{p}<0.001)(95 \% \mathrm{Cl} 1.292-2.272)$.
\end{abstract}

Conclusion: A current smoking status and a nicotine dependence were both independently associated with an increased risk for chronic LBP and/or chronic radicular neuropathic leg pain.

Keywords: Chronic pain; cross-sectional studies; low back pain; neuralgia; nicotine; radiculopathy; sciatica; smoking; tobacco use disorder.

\section{Öz}

Amaç: Mevcut sigara içme durumunun ve yüksek nikotin bağımlıı̆ının kronik bel ağrısı (KBA) ve/veya radiküler nöropatik ağrı ile ilişkili olup olmadığını değerlendirmek.

Gereç ve Yöntem: Çalışma, ilk uygun ardışık 120 hasta ile kesitsel bir çalışma olarak tasarlandı. Demografik veriler, ağrı yoğunluğu, en kötü ağrı konumu, en distal ağrı radyasyonu, DN4 anketi, STarT bel sağlığı tarama ölçeği ve Fagerström test sonuçları ilk muayene sırasında toplanmıştır. Kronik bel ağrısı olmayan, yaş ve cinsiyet uyumlu bir kontrol grubu $(n=50)$ alındı.

Bulgular: Kronik ağrı grubunda, ortalama ağrı şiddeti skoru $(p=0,037)$, toplam DN4 skoru $(p=0,002)$, STarT Back ölçeği $(p=0,006)$, en kötü ağrı konumu $(p=0,023)$ ve en distal ağrı radyasyonu $(p=0,049)$ açısından sigara içenler ve yaşam boyu sigara içmeyenler arasında anlamlı bir fark vardı. Ortalama toplam DN4 puanı, günlük içilen sigara sayısında karşlık gelen artışla beraber artmıştır $(p=0,002)$. Mevcut sigara içenlerde KBA ve bel ile ilişkili bacak ağrısı gelişimi için OR: $3.071(p=0,013)(\% 95 \mathrm{Cl} 1.268-7.438)$ ve kronik radiküler nöropatik bacak ağrısı gelişimi için OR: $6.484(p<0,001)(\% 95 \mathrm{Cl} 2.323-18.099)$ idi. Fagerström test puanındaki her bir birimlik artış için, KBA ve bel ile ilişkili bacak ağrısı olasılığı \%40,71 artmıştı $(\mathrm{p}=0,008)(\% 95 \mathrm{Cl}$ 1.095-1.809) ve kronik radiküler nöropatik bacak ağrısı olasılığı \%71,3 artmıştı ( $p<0,001)$ (\%95 Cl 1.292-2.272).

Sonuç: Mevcut sigara içme durumu ve nikotin bağımlılığı, bağımsız olarak KBA ve/veya kronik radiküler nöropatik ağrı için artan bir risk ile ilişkiliydi.

Anahtar sözcükler: Kronik ağrı; kesitsel çalışmalar; bel ağrısı; nevralji; nikotin; radikülopati; siyatik; sigara içmek; tütün kullanımı.

\footnotetext{
'Physiotherapy Outpatients, Karin Grech Hospital, Guardamangia Hill, Pieta PTA 1312, Malta;

MSc Clinical Management of Pain (Headache), University of Edinburgh, UK

${ }^{2}$ Department of Physiotherapy, Ministry for Health, Malta;

Department of Physiotherapy, University of Malta Faculty of Health Sciences, Msida, Malta

${ }^{3}$ Department of Statistics and Operations Research, University of Malta Faculty of Science, Msida, Malta

${ }^{4}$ University of Malta, Faculty of Health Sciences, Msida, Malta
}

Submitted (Başvuru tarihi) 14.01.2020 Accepted after revision (Düzeltme sonrası kabul tarihi) 10.01.2021 Available online date (Online yayımlanma tarihi) 29.06.2021

Correspondence: Dr. Emanuel Schembri. 72, Carini Street, St Venera, Malta. SVR 1404.

Phone: +35679277764 e-mail: emanuel.a.schembri@gov.mt

(c) 2021 Turkish Society of Algology 


\section{Introduction}

\section{Background information on the field of study}

In 2016, low back pain (LBP) was one of the five leading causes of disability, causing approximately 57.6 million years lived with disability. ${ }^{[1]}$ Most patients who suffer from acute LBP recover within 6 weeks; nonetheless, symptoms persist in $5-10 \%$ of LBP sufferers, with a risk of becoming chronic. ${ }^{[2]}$ The transition to chronic LBP imposes a multidimensional burden on the person's life with a significant impact on the personal, social, and economic aspects. ${ }^{[3]}$ Amongst low back disorders, radiculopathies and subsequently radicular pain are considered the most prevalent neuropathic pain condition, ${ }^{[4]}$ defined by the International Association for the Study of Pain as "pain caused by a lesion or disease of the somatosensory nervous system."[5] This possibly explains their more persistent and disabling nature as compared to axial $\mathrm{LBP}_{1}^{[6]}$ evident by refractoriness to treatment, including strong analgesics. ${ }^{[7]}$ Cigarette smoking is known to cause adverse effects on multiple organ systems of the body. Systematic reviews revealed that smoking was associated with $\mathrm{LBP}^{[8-10]}$ and with sciatica. ${ }^{[11,12]}$ Furthermore, smoking was associated with the development of various neuropathies including carpal tunnel syndrome, ${ }^{[13]}$ diabetic neuropathy, ${ }^{[14]}$ ulnar neuropathy, ${ }^{[15]}$ and cubital tunnel syndrome. ${ }^{[16]}$ Importantly, the presence of such neuropathies is the prerequisite for the onset of neuropathic pain. ${ }^{[4]}$

Smokers reported higher pain levels that necessitate greater use of analgesics, with pain impacting more negatively on activities of daily living. [17] Similarly, Khan et al. ${ }^{[18]}$ found that compared to non-smokers, current smokers suffered from a higher pain intensity. Furthermore, pain interference, physical functioning, depression, and anxiety, all of which form part of the STarT Back tool, ${ }^{[19]}$ were significantly $(p<0.001)$ more prevalent in current smokers. ${ }^{[18]}$ A search in PubMed using the terms "neuropathic pain and smok" yielded a publication penned by Çelik et al. ${ }^{[20]}$ To the authors' best knowledge, this is probably the only cross-sectional study dealing specifically with nicotine dependence and neuropathic pain, which the current authors read with interest. The study used the DN4 and the Fagerström test for Nicotine Dependence, and it found a significant difference $(p<0.05)$ in the number of packets of cigarettes smoked per year between the individuals with and without neuropathic pain. However, the pathoanatomical etiology causing neuropathic pain could not be established, hence hindering the analysis of specific patient subgroups, which could be more prone to the deleterious effects of smoking on neuropathic pain. Furthermore, it did not specify if former smokers were included and accounted for in the results, and it did not consider psychological factors that can potentially mediate both smoking habits and neuropathic pain. ${ }^{[17]}$ This paper reports on a cross-sectional study which aims to investigate the association between a population of chronic LBP sufferers, which incorporated a subset of patients suffering from chronic radicular neuropathic pain, with nicotine dependence.

The objectives of this study were to investigate the following questions:

1. Do current smokers have a higher pain intensity, higher DN4 score, and STarT Back scores compared to lifetime non-smokers?

2. Do current smokers have an increased risk for chronic LBP, lumbar related leg pain (sciatica), and radicular neuropathic leg pain compared to lifetime non-smokers?

3. Does a higher nicotine dependency increase the risk for chronic LBP, lumbar related leg pain (sciatica), and chronic radicular neuropathic leg pain?

\section{Material and Methods}

\section{Study design and setting}

The research committee at a local rehabilitation hospital in Malta, Europe, approved the research method and ethical considerations undertaken in this study (04/03/2019). A signed written informed consent was obtained from all the participants. The study was designed as a cross-sectional study in which the principal investigator (ES) examined all the eligible patients who, between March and October 2019, attended for their initial physiotherapy assessment due to chronic LBP or lumbar related leg pain (sciatica) or chronic radicular neuropathic leg pain. For this study, the term LBP referred to pain arising from the lower thoracic margin extending distally to the horizontal gluteal folds, while pain in the lower limb comprised any location distal to the horizontal gluteal fold. Chronic pain was defined as pain for more than 3 consecutive months. ${ }^{[21]}$ 
Since sciatica is a symptom rather than a diagno$\mathrm{sis}{ }^{[22]}$ with noticeable variation in the diagnostic criteria of what comprises sciatica, ${ }^{[11]}$ the DN4 was used to systematically categorize lumbar related leg pain with a definite neuropathic pain component (positive DN4 score, $\geq 4$ ) or caused solely by nociceptive referred pain, probably due to convergence mechanisms (negative DN4 score, $\leq 3$ ).

The patients were seen at the Musculoskeletal Physiotherapy Outpatients Department at a local rehabilitation hospital in Malta, Europe. The number of cases referred from the sole state acute general hospital in Malta during the study period determined the final sample size $(n=120)$ (Fig. 1), hereunder referred to the "chronic pain group." An age- and gendermatched chronic LBP and lumbar related leg pain (sciatica) free group, hereunder referred to the "control group," who did not suffer from chronic LBP and lumbar related leg pain (sciatica) for the past year $(n=50)$ were also recruited (Fig. 2). The control group was used as reference when calculating the odds ratios for chronic LBP and radicular neuropathic pain. All of the patients included in this study form part of an ongoing observational study evaluating the management and outcome of patients with chronic spinal pain who have been referred to the Musculoskeletal Physiotherapy Outpatients Department at the local rehabilitation hospital. This paper was written according to the STROBE statement. ${ }^{[23]}$

\section{Participants}

The criteria for eligibility within the chronic pain group included patients of both sexes (1) above 18 years of age; (2) referred to the Musculoskeletal Physiotherapy Outpatient's facilities for chronic LBP and/or lumbar related leg pain (sciatica); (3) with pain duration of $\geq 3$ months; and (4) who were either lifetime non-smokers or current smokers.

Patients were excluded from the sample if they were living with a partner/relative who smoked, had other severe musculoskeletal pain, with known diabetic neuropathy or known length-dependent polyneuropathy, major comorbidity (e.g., malignant disorders or sepsis) or with pain of unknown origin, complex regional pain syndrome, headache, visceral pain, severe alcoholism or substance abuse, cognitive impairment or intellectual disability, and severe

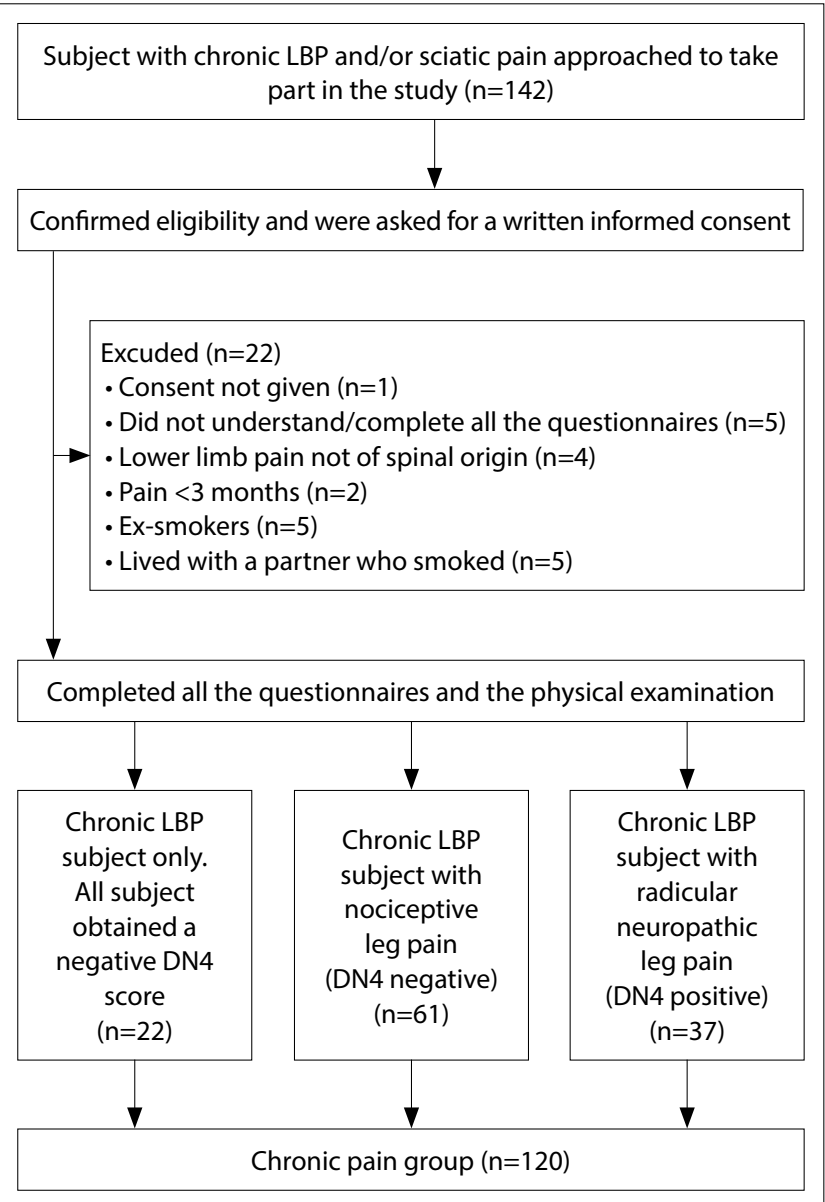

Figure 1. Flow diagram of the chronic pain participants in the study.

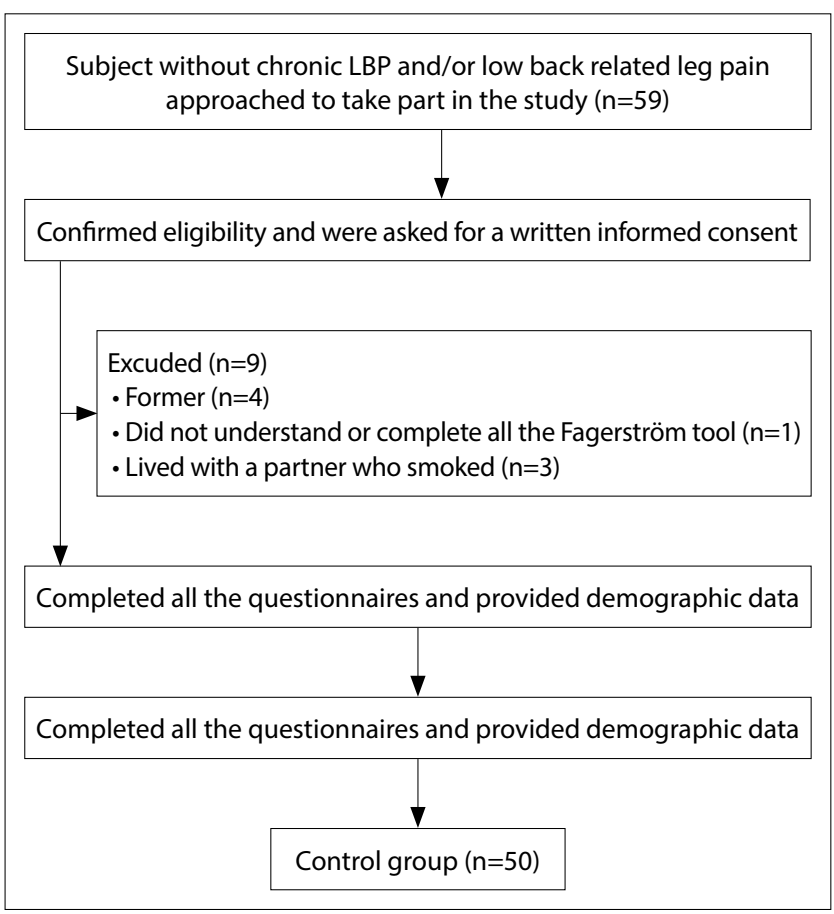

Figure 2. Flow diagram of the control group in the study.

depression or psychosis and if they were unable to understand or complete all of the questionnaires. Former smokers who, for the purpose of this study, 
were defined previously having engaged in smoking activities but who currently have abstained from such practice were excluded as well. Ex-smokers were excluded due to evidence demonstrating that the deleterious effects of smoking can last up to 30 years following cessation. Therefore, the effects can potentially reduce but cannot completely eliminate the risk of the onset of LBP. ${ }^{[1]]}$ Their exclusion helped avoid introducing confounding factors related to how long ago they had stopped smoking and any resumption of smoking behaviors, which would complicate the interpretation of the results.

The same criteria were applied to the control group except that they must have not complained of chronic LBP and/or lumbar related leg pain (sciatica) over the past year.

\section{Patient-reported outcome measures Demographics}

Patient demographic data including age, gender, and pain chronicity (in years) were recorded.

\section{Pain assessment}

Pain intensity was assessed using three separate numeric pain rating scales (NRS) $(0-10)$ for lowest, average and highest pain intensity, with anchors "no pain" and "worst thinkable pain." The NRS was preferred over the visual analog scale (VAS) since previous data ${ }^{[24]}$ showed that the mean age of our clinical population was $58.9 \pm 13.5$ years,. Evidence suggests that this population could find difficulty in completing the visual analog scale and that this scale was associated with a higher frequency of incomplete scores. ${ }^{[25]}$

The worst pain location was categorized as either in the low back or in the lower limb. The most distal pain radiation was recorded, and it was categorized into five sections, namely, the low back, knee level, upper calf, lower calf and/or ankle, and in the foot. ${ }^{[26]}$

The number of oral analgesic drug classes currently being used by the chronic pain group, irrespective of dosage and frequency, was collected using selfreported information provided by the patient as part of the drug history recorded in the physiotherapy assessment. The five main analgesic drug classes included acetaminophen, non-steroidal anti-inflam- matory drugs, gabapentinoids, antidepressants, and opioids. For patients taking a combination of analgesic drugs, the number of current analgesic drug classes consumed was calculated as two or more depending on the specific formulation of the medication involved.

To differentiate between neuropathic pain and nociceptive pain, the English DN4 questionnaire ${ }^{[27]}$ was administered during the initial physiotherapy assessment. The DN4 is one of the most sensitive neuropathic pain diagnostic questionnaires, ${ }^{[28]}$ being highly capable of discriminating between neuropathic pain and nociceptive pain. ${ }^{[29]}$ The DN4 was validated in patients with LBP due to herniated discs, spinal stenosis, degenerative disc disease, degenerative lumbar spine, spinal surgery, and lumbar scoliosis. A cutoff score of $\geq 4$ in the DN4 obtained a sensitivity of $80 \%$ and a specificity of $92 \%$ in diagnosing neuropathic pain in LBP subjects. ${ }^{[30]}$ Each patient was asked to describe his or her pain according to the first seven neuropathic pain descriptors in the DN4 to calculate the DN4 Interview subscore (range 0-7). A sensory examination was carried out using a SENSELab ${ }^{\text {TM }}$ Brush-05 (Somedic SenseLab $A B$, Sösdala, Sweden) to assess for hypoesthesia to brushing and brush allodynia, while a $5.1 \mathrm{~g}$ SemmesWeinstein monofilament (Baseline ${ }^{\oplus}$ Tactile Monofilaments $^{\mathrm{TM}}$, Fabrication Enterprises Inc, White Plains, NY, USA) was used to assess hypoesthesia to fine tactile stimuli, as carried out in the original DN4 validation study. ${ }^{[27]}$ Two repetitions of each of the three sensory tests were performed in the most painful area and compared to the corresponding contralateral aspect. In case of an inconsistent result between the two test repetitions, the result for the specific testing modality was scored as a normal response. In patients with lumbar related leg pain but having their worst pain location in the low back area, the DN4 was first scored for the low back. If the DN4 score was negative, the DN4 was re-administered in the painful lumbar related leg area. If the latter DN4 score was positive, this was used for statistical analysis. Each of the ten questions in the total DN4 score has a nominal scale with two possible responses (yes or no), and the total score was generated by summing the binary scores of all the ten items. Both the DN4 Interview subscore and the total DN4 score were included in the statistical analysis. 


\section{Smoking and nicotine dependence}

The Fagerström Test for Nicotine Dependence was initially developed by Fagerström and Schneider, ${ }^{[31]}$ and then revised by Heatherton et al. ${ }^{[32]}$ This test quantifies the nicotine addiction risk and consists of six questions with a possible total score ranging from 0 to 10 . A score of $0-2$ indicates very low nicotine dependence, 3-4 low dependence, 5 medium dependence, 6-7 high dependency, and 8-10 specifies very high dependence. Item number 4 of this tool quantifies the number of cigarettes smoked per day clustered into four categories 10 or less, $11-20,21-30$, or more than 31 cigarettes per day, with a higher cigarette consumption contributing to a higher final score on the questionnaire. The total Fagerström score and item number 4 of this questionnaire were included in the statistical analysis as two separate variables.

\section{Outcome predictor}

The STarT Back tool ${ }^{[19]}$ includes treatment modifiable domains such as the spread of pain, disability, and psychological factors. The STarT Back tool's overall score ranges from 0 to 9 , which is calculated by summing up all the positive responses reported. The STarT Back distress subscales include fear, catastrophizing, depression, anxiety, and bothersomeness, and their scores range from 0 to 5 . The STarT Back distress subscale can ably replace administering multiple unidimensional psychological measures at initial assessment as a first-line screening measure for psychological distress. This was evidenced in a secondary care physiotherapy outpatient setting where the individual distress STarT Back tool items were related to several unidimensional psychological measures. ${ }^{[33]}$ The brevity of this tool is advantageous in a busy outpatient department. Furthermore, both the total STarT Back score but notably the distress subscale scores predict pain intensity in an outpatient physical therapy setting. ${ }^{[34]}$ In addition, the STarT Back tool predicted disability in subjects with chronic $\mathrm{LBP}_{1}^{[3,35]}$ in subjects attending a physiotherapy outpatient setting ${ }^{[36]}$ and in a secondary care physiotherapy outpatient setting. ${ }^{[37]}$ This is not surprising since the STarT Back Tool was designed to predict future disability in LBP subjects. ${ }^{[19]}$ Both the STarT Back distress subscore and the total score were included in the statistical analysis.
The STarT Back tool and the Fagerström Test for Nicotine Dependence were administered after the clinical examination, to minimize bias of the principal investigator carrying out the assessments. Participants were aware of the scope of the study but not of the content of the individual questionnaires carried out, hence to obtain single blinding. The patients were instructed to complete the questionnaires on paper on their own but were allowed to ask for help if needed. Patients with missing data were excluded from participation in this study.

\section{Control group}

The participants within the control group reported all the above measures except those related to pain, since they had to be not suffering from chronic LBP or lumbar related leg pain for the past year.

\section{Statistical analysis}

Statistical testing and models were utilized to analyze the data, where a 0.05 level of significance was used for all the tests carried out. The Independent samples t-test was used to compare mean patient characteristics scores between two independent groups clustered by smoking status (yes, no). The patient characteristics included the lowest, average, and highest pain scores, pain chronicity, DN4 Interview, and DN4 total scores, Fagerström score, STarT Back distress, and STarT Back total scores, age, and the number of analgesic drug classes consumed.

The One-Way ANOVA test was used to compare the mean Fagerström and total DN4 scores, both ranging from 0 to 10, between four categories of the number of cigarettes smoked daily $(0-10,11-20,21-30,31$ or more). The Chi-square test was used to test the association between two categorical variables. One of these variables was smoking status (yes and no), while the other variable was gender (male and female), worst pain location (lower back and lower limb), most distal pain radiation (lower back, knee, upper calf, and lower calf/ankle, foot), or DN4 score category (positive, and negative).

The difference of two proportion z-test was used to compare the percentage of patients whose worst pain was located in the lower limb between males and females and between smokers of 10 cigarettes or less and smokers of more than 20 
Table 1. Mean patient characteristics scores grouped by smoking status

\begin{tabular}{lccccc}
\hline Patient characteristics & Smoking status & Sample size & Mean & SD & p \\
\hline Age (years) & Yes & 40 & 57.10 & 11.395 & 0.094 \\
& No & 80 & 61.38 & 13.828 & \\
Lowest pain score (NRS) & Yes & 40 & 2.35 & 2.248 & 0.529 \\
Average pain score (NRS) & No & 80 & 2.08 & 2.249 & \\
& Yes & 40 & 6.15 & 2.282 & $\mathbf{0 . 0 3 7}$ \\
Highest pain score (NRS) & No & 80 & 5.15 & 2.521 & \\
& Yes & 40 & 8.78 & 1.732 & 0.285 \\
Pain chronicity (years) & No & 80 & 8.44 & 1.566 & \\
& Yes & 40 & 4.85 & 6.269 & 0.583 \\
Number of analgesic drug classes consumed & No & 80 & 5.69 & 8.665 & \\
& Yes & 40 & 1.00 & 1.038 & 1.000 \\
DN4 Interview score (range 0-7) & No & 80 & 1.00 & 0.981 & \\
DN4 total score (range 0-10) & Yes & 40 & 2.53 & 1.811 & $\mathbf{0 . 0 0 0}$ \\
Fagerström score (range 0-10) & No & 80 & 1.34 & 1.575 & \\
& Yes & 40 & 3.35 & 2.282 & $\mathbf{0 . 0 0 2}$ \\
STarT Back Distress score (range 0-5) & No & 80 & 2.05 & 2.104 & \\
STarT Back total score (range 0-9) & Yes & 40 & 4.33 & 2.269 & $\mathbf{0 . 0 0 0}$ \\
& No & 80 & 0.00 & 0.000 & \\
\hline SD:Stan & Yes & 40 & 2.73 & 1.261 & $\mathbf{0 . 0 3 7}$ \\
& No & 80 & 2.15 & 1.476 & \\
& Yes & 40 & 5.38 & 1.904 & $\mathbf{0 . 0 0 6}$ \\
& No & 80 & 4.31 & 2.016 & \\
\hline
\end{tabular}

SD: Standard deviation; NRS: Numeric pain rating scales.

cigarettes. Multinomial regression analysis was used to relate a continuous dependent variable (DN4) to ten predictors collectively. A backward procedure was used to identify the parsimonious model, which includes solely the significant predictors. Logistic regression analysis was used to relate a categorical dependent variable (chronic LBP or chronic low back-related neuropathic leg pain) to four predictors, including Fagerström score, smoking status, age, and gender of the patient. The odds ratios and their $95 \%$ confidence interval were computed for ease of interpreting the results. All statistical analyses were performed using the SPSS version 25 statistics package (SPSS Inc., Chicago, IL, USA).

\section{Results}

\section{Sample description}

The baseline demographic and descriptive data of the 120 participants in the chronic pain group
Table 2. Association between worst pain location and the current smoking status

\begin{tabular}{|c|c|c|c|}
\hline & \multicolumn{2}{|c|}{ Smoking status } & \multirow[t]{2}{*}{ Total } \\
\hline & Yes & No & \\
\hline \multicolumn{4}{|l|}{ Worst pain location } \\
\hline \multicolumn{4}{|l|}{ Lower back } \\
\hline Count & 9 & 35 & 44 \\
\hline Percentage & 22.5 & 43.8 & 36.7 \\
\hline \multicolumn{4}{|l|}{ Lower limb } \\
\hline Count & 31 & 45 & 76 \\
\hline Percentage & 77.5 & 56.3 & 63.3 \\
\hline \multicolumn{4}{|l|}{ Total } \\
\hline Count & 40 & 80 & 120 \\
\hline Percentage & 100.0 & 100.0 & 100.0 \\
\hline
\end{tabular}

$X^{2}(1)=5.185 ; p=0.023$.

are presented in Tables $1-3$. The control group was adequately age $(p=0.944)$ and gender $(p=0.873)$ matched to the chronic pain group. However, 
Table 3. Association between most distal pain radiation in the lower limb and smoking status

\begin{tabular}{lll}
\hline & \multicolumn{3}{l}{ Smoking status } \\
\cline { 2 - 3 } Yes Nota
\end{tabular}

Most distal pain radiation

Lower back

$\begin{array}{lccc}\text { Count } & 2 & 20 & 22 \\ \text { Percentage } & 5.0 & 25.0 & 18.3\end{array}$

Knee

$\begin{array}{lccc}\text { Count } & 5 & 15 & 20 \\ \text { Percentage } & 12.5 & 18.8 & 16.7\end{array}$

Upper calf

$\begin{array}{lccc}\text { Count } & 4 & 4 & 8 \\ \text { Percentage } & 10.0 & 5.0 & 6.7\end{array}$

Lower calf/ankle

$\begin{array}{llll}\text { Count } & 9 & 13 & 22\end{array}$

$\begin{array}{llll}\text { Percentage } & 22.5 & 16.3 & 18.3\end{array}$

Foot

$\begin{array}{lccc}\text { Count } & 20 & 28 & 48 \\ \text { Percentage } & 50.0 & 35.0 & 40.0\end{array}$

Total

$\begin{array}{lccc}\text { Count } & 40 & 80 & 120 \\ \text { Percentage } & 100.0 & 100.0 & 100.0\end{array}$

In Table 3, only $10 \%$ of the expected counts are $<5$, which is less than the threshold value of $20 \%$, so Table 3 should remain the same. 1 cell $(10.0 \%)$ have expected count $<5$. The minimum expected count is 2.67 .

there was a statistically significant difference $(p=0.01016)$ in the number of current smokers between the control group (14.0\%) and the chronic pain group (33.3\%).

\section{Current smokers versus lifetime non-smokers in the chronic pain group}

Table 1 shows that between the two groups, there was a significant difference in the mean pain score $(p=0.037)$, mean DN4 Interview subscore $(p<0.001)$, mean total DN4 score $(p=0.002)$, mean STarT Back Distress subscore $(p=0.037)$, and mean total STarT Back score $(p=0.006)$. However, there were no significant differences between the two groups in the other variables.

\section{Smoking status and pain characteristics}

Table 2 shows a significantly $(p=0.023)$ larger percentage of the current smokers (77.5\%) than nonsmokers (56.3\%) reporting the lower limb as their
Table 4. Association between DN4 score categories and smoking status

\begin{tabular}{cccc}
\hline & \multicolumn{2}{c}{ Smoking status } & Total \\
\cline { 2 - 3 } & Yes & No & \\
\hline DN4 & & & \\
Positive $(\geq 4)$ & & & \\
$\quad$ Count & 19 & 18 & 37 \\
$\quad$ Percentage & 47.5 & 22.5 & 30.8 \\
Negative $(\leq 3)$ & & & \\
$\quad$ Count & 21 & 62 & 83 \\
$\quad$ Percentage & 52.5 & 77.5 & 69.2 \\
Total $\quad$ & & & \\
$\quad$ Count & 40 & 80 & 120 \\
$\quad$ Percentage & 100.0 & 100.0 & 100.0 \\
\hline
\end{tabular}

$X^{2}(1)=7.815 ; p=0.005$.

Table 5. Mean Fagerström scores grouped by number of cigarettes smoked daily

\begin{tabular}{lccc}
\hline $\begin{array}{l}\text { Cigarettes } \\
\text { daily smoked }\end{array}$ & $\begin{array}{c}\text { Sample } \\
\text { size }\end{array}$ & $\begin{array}{c}\text { Mean Fagerström } \\
\text { score }\end{array}$ & SD \\
\hline $0-10$ & 11 & 1.73 & 1.272 \\
$11-20$ & 17 & 4.35 & 1.412 \\
$21-30$ & 9 & 6.33 & 1.000 \\
31 or more & 3 & 7.67 & 0.577 \\
\hline
\end{tabular}

SD: Standard deviation; $F(3,36)=30.47 ; p<0.001$.

worst pain location. Moreover, there was a significantly $(p=0.049)$ larger percentage of the current smokers $(72.5 \%)$ than non-smokers $(51.3 \%)$ reporting most distal pain radiation in the foot/lower calf/ankle (Table 3 ). Table 4 shows a significantly $(p=0.005)$ larger percentage of current smokers $(47.5 \%)$ than non-smokers (22.5\%) who obtained a positive total DN4 score.

\section{Dose-response effect}

There was a significant difference in the mean total DN4 score between categories of the number of cigarettes smoked daily ( $p=0.002$ ) (Fig. 3). Table 5 shows that the mean Fagerström score increases significantly with an increase in the number of cigarettes smoked daily $(p<0.001)$ with the mean Fagerström score increasing from 1.73 for light smokers (0-10 cigarettes daily) to 7.67 for heavy smokers (more than 30 cigarettes daily). Comparison between light smokers and heavy smokers 


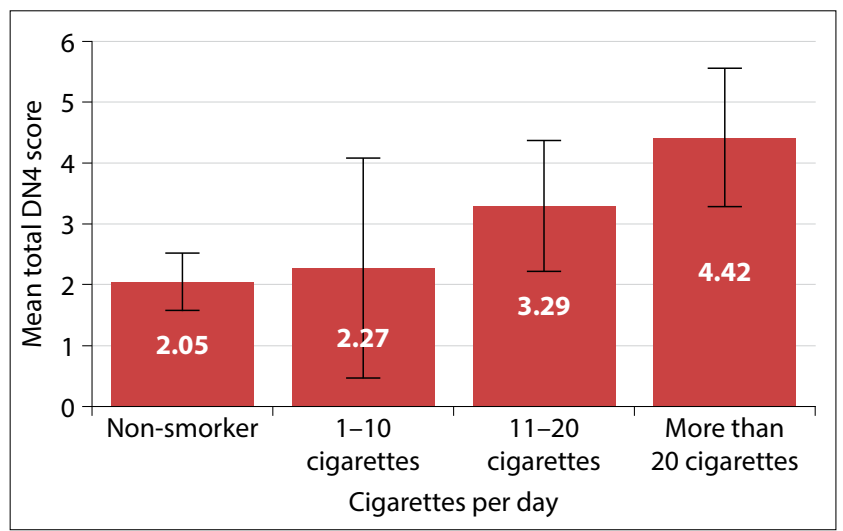

Figure 3.95\% confidence intervals for the mean total DN4 score by the number of cigarettes smoked daily.

across the ten outcome variables was conducted. Except for the Fagerström score $(p=0.026)$, the differences in the mean scores of the other variables were not significant.

\section{Relationship between the presence of neuropathic pain and patient characteristics}

Regression analysis was used to relate DN4 score to ten outcome variables, which was adjusted for age, gender, average pain intensity, STarT Back distress and total scores, Fagerström score and the number of cigarettes consumed daily. Using a backward procedure, Table 6 shows the four significant predictors of chronic radicular neuropathic pain, which included lower limb as worst pain location $(p=0.035)$, the foot as the most distal pain radiation location ( $p=0.001)$, the total STarT Back score $(p=0.013)$, and the Fagerström score $(p=0.014)$.

\section{Current smoking status and nicotine} dependence as risk factors for chronic LBP and chronic radicular neuropathic leg pain

\section{Current smoker status}

The OR that a current smoker has chronic LBP, including lumbar related leg pain (sciatica), rather than being pain-free was 3.071 times $(p=0.013,95 \% \mathrm{Cl}$, 1.268-7.438) that of a lifetime non-smoker. The odds that a current smoker has chronic radicular neuropathic leg pain (positive DN4 score) rather than being pain-free, is 6.484 times $(p<0.001,95 \% \mathrm{Cl}, 2.323-$ 18.099 ) that of a lifetime non-smoker.

\section{Nicotine dependence- Fagerström score}

For every 1 unit increase in the Fagerström score, the odds that a patient has chronic LBP, including lumbar related leg pain (sciatica), rather than being pain-free increases by $40.7 \%(\mathrm{p}=0.008,95 \% \mathrm{Cl}, 1.095-1.809)$. For every 1 unit increase in the Fagerström score, the odds that a patient has chronic radicular neuropathic leg pain (DN4 positive score) rather than being pain-free increases by $71.3 \%(p<0.001,95 \% \mathrm{Cl}$, 1.292-2.272).

\section{Discussion}

This cross-sectional study showed that a mean higher DN4 score, in participants suffering from chronic LBP with or without lumbar relate leg pain, corresponded to a higher daily cigarette consumption. Furthermore, a current smoking status and a higher

Table 6. Regression model relating the DN4 score to patient characteristics

\section{Tests of between-subjects effects}

\section{Dependent variable: DN4}

\begin{tabular}{|c|c|c|c|c|c|}
\hline Patient characteristics & Sum of squares & df & Mean square & $\mathbf{F}$ & $\mathbf{p}$ \\
\hline Corrected model & 242.714 & 7 & 34.673 & 10.931 & 0.000 \\
\hline Intercept & 11.681 & 1 & 11.681 & 3.683 & 0.058 \\
\hline Worst location & 14.506 & 1 & 14.506 & 4.573 & 0.035 \\
\hline Most distal pain radiation & 65.384 & 4 & 16.346 & 5.153 & 0.001 \\
\hline Fagerström score & 19.579 & 1 & 19.579 & 6.173 & 0.014 \\
\hline STarT back total score & 20.115 & 1 & 20.115 & 6.342 & 0.013 \\
\hline Error & 355.253 & 112 & 3.172 & & \\
\hline Total & 1338.000 & 120 & & & \\
\hline Corrected total & 597.967 & 119 & & & \\
\hline
\end{tabular}

R Squared $=0.406$. 
Fagerström score were both independently associated with an increased risk for chronic LBP and radicular neuropathic pain.

\section{Nicotine addiction}

The paper by Çelik et al. ${ }^{[20]}$ probably provides the most direct comparison to the current study. Their study utilized the DN4 and the Fagerström score, and they found that persons with a positive DN4 score consumed a higher number of cigarette packets per year compared to those who obtained a negative DN4 score $(<0.05)$. Similarly, we found that the mean total DN4 score increased with a corresponding increase in the number of cigarettes smoked daily (Fig. 3) $(p=0.002)$. Furthermore, Çelik et al. ${ }^{[20]}$ obtained an OR of $1.29(\mathrm{Cl}, 1.14-1.46)$ for each standard deviation increase (2.7) in the Fagerström score. However, results from our study show that every 1 unit increase in the Fagerström score yielded an OR of $1.407(\mathrm{Cl}$, 1.095-1.809) for chronic LBP and lumbar related leg pain and an OR of $1.713(\mathrm{Cl}, 1.292-2.272)$ for chronic radicular neuropathic pain. These minor differences in the results could be explained by the different methodologies adopted to present the results (standard deviation increase vs. 1 unit increase in Fagerström score) and also by the fact that Çelik et al. ${ }^{[20]}$ complied their OR's with subjects having a negative DN4 score, yet these could still be experiencing nociceptive pain, while in our study comparison was made to the control group who were free from chronic pain.

Shemory et al. ${ }^{[38]}$ found that nicotine dependence yielded a relative risk of $4.489(p<0.001,95 \% \mathrm{Cl}$, 4.471-4.506) for LBP. However, this study did not provide an insight into the relative risk of nicotine dependence for developing chronic LBP, and it did not mention the diagnostic criteria for nicotine dependence, hence hindering direct comparison and possibly explaining the difference in ORs. Shaw et al. ${ }^{[39]}$ examined only men with acute LBP, and they found that nicotine addiction leads to an increased chance for the chronification of $\mathrm{LBP}(\mathrm{OR}=2.49,95 \% \mathrm{Cl}, 1.15-5.40)$ among other psychological variables. However, direct comparison to our study is hindered since Shaw et al. ${ }^{[39]}$ used the Diagnostic Interview Schedule-III-R to asses for nicotine dependence and the subjects were experiencing their first LBP symptoms, while in our study the subjects were already suffering from chronic LBP. Zvolensky et al. ${ }^{[40]}$ found that after adjust- ing for various socio-demographic variables, persons with nicotine dependence were almost twice as likely to report chronic neck or back pain $(\mathrm{OR}=1.95,95 \% \mathrm{Cl}$, $1.41-2.68)$. Besides, they found that $30 \%$ of the persons suffering from past year or lifetime chronic neck or back pain were current smokers. However, nicotine dependence was assessed through the World Health Organization's Composite International Diagnostic Interview, hence hindering direct comparison with our study. Overall, these three studies ${ }^{[38-40]}$ provide higher ORs for developing LBP in subjects with nicotine dependence compared to our study (OR 1.407). However, this could be partly due to the study design, the different diagnostic criteria for nicotine dependence and the way results were presented.

\section{Smoking status}

Various reviews ${ }^{[8-12,41,42]}$ were conducted exploring the relationship between LBP, sciatic pain, and smoking. However, direct comparison is hugely hindered by the lack of standardization on what defines sciatica coupled with the lack of details regarding whether the neuropathic pain component was assessed at all in these studies. Such broad definitions and diagnostic procedures will affect the inclusion and exclusion criteria for the respective studies and hence will affect the ORs. This was stressed by Cook et al. ${ }^{[11]}$ who found "inconsistent operational definitions" of what comprised sciatica raging from a medical diagnosis during hospital admission to referred pain below the knee or a definitive or non-definitive area in the lower limb. All these reviews evaluated smoking status only, rather than concurrently examining nicotine dependence, which encapsulates a more extensive biopsychosocial element. In addition, certain reviews ${ }^{[10-12]}$ did not assess the effect of smoking on chronic sciatica. Hence, the conclusion of the following studies must be considered in the light of such discrepancies.

The umbrella review by Parreira et al. ${ }^{[9]}$ identified a systematic review by Ferreira et al. ${ }^{[8]}$ (AMSTAR Grade $6, n=1,960$ ) evaluating chronic LBP in twin subjects. The latter review found that smoking was significantly associated with LBP (pooled OR $=3.0,95 \% \mathrm{Cl}$, 2.8-3.3), which is very similar to our results. However, this twin study did not mention explicitly if their OR is valid for chronic LBP, but rather this review provided a pooled OR was for the most prolonged LBP 
symptom. With regard to sciatica, the umbrella review ${ }^{[9]}$ identified a systematic review by Cook et al. ${ }^{[1]]}$ (AMSTAR Grade 7, $n=7,701$ ) evaluating risk factors for first time incidence sciatica. This review is hampered by the lack of diagnostic criteria of sciatica, which will affect the ORs. The OR for current smoker ranged from $1.5(95 \% \mathrm{Cl}, 1.1-2.1)$ to $9.6(95 \% \mathrm{Cl}, 1.7-$ 53.0). Considering that $81.7 \%$ of our subjects were experiencing lumbar related leg pain, our OR (3.071) fits within the spectrum of ORs provided by Cook et al. ${ }^{[11]}$ However, the standardized approach used in our study could provide a more reliable and reproducible result.

A scoping review by Green et al. ${ }^{[42]}$ identified a metaanalysis by Shiri et al. ${ }^{[41]}$ which found that a current smoking status yielded an OR of $1.79(95 \% \mathrm{Cl}, 1.27-$ 2.50, $n=31,811)$ for developing chronic LBP. Furthermore, Green et al. ${ }^{[42]}$ found a systematic review by Shiri et al. ${ }^{[10]}$ assessing the association between smoking and lumbar radicular pain. According to this review, lumbar radicular pain was present in case of restriction in the straight leg raise test or other clinical signs of rhizopathy. However, this systematic review ${ }^{[10]}$ is hindered by the lack of standardization and detail with regard to what clinical testing procedures were used. In addition, a systematic review ${ }^{[3]}$ has shed doubts on the diagnostic accuracy of the straight leg raise test in diagnosing pain originating from lumbar disc herniation, which can explain the lower OR in their study. ${ }^{[10]}$

A meta-analysis by Shiri and Falah-Hassani ${ }^{[12]}$ evaluated the effect of smoking on the risk of sciatica. For current smokers, the pooled adjusted OR was 1.64 (95\% Cl, 1.24-2.16, $\mathrm{n}=10,853)$ for lumbar radicular pain, and for clinically verified sciatica the OR was 1.35 (95\% Cl, 1.09-1.68, $\mathrm{n}=110,374)$. Furthermore, this meta-analysis did not provide information on what clinical tests were used to provide a diagnosis of "clinically verified sciatica," and it only mentions signs of nerve root irritation, yet these can vary from negative sensory findings to positive ones, with negative sensory findings having a higher diagnostic value for the presence of neuropathic pain. ${ }^{[4]}$

\section{Strengths and limitations of the study}

The effects of a previous smoking habit can significantly outlast the smoking free period. ${ }^{[1]}$ Hence, one of the strengths of this study was the exclusion of former smokers to avoid any confounding factors affecting results such as when smoking was stopped, any smoking cessation, and resumption of smoking behaviors. This study assessed nicotine dependence apart from solely assessing smoking status together with the number of cigarettes consumed daily, henceforth addressing a possibly, treatment modifiable, and dimension within the biopsychosocial construct of chronic LBP. To decrease bias, every effort was made to ensure that each patient completed all the questionnaires.

This study had to overcome the inherent difficulties in quantifying sciatica. Sciatica can originate both from neuropathic and nociceptive pain, yet these cannot be properly quantified without a standard examination. Most of the cited papers ${ }^{[9-12,42]}$ reported that a clinical examination was conducted, yet specific details of such examination were not mentioned, hence hindering reproducibility. Besides, most of the cited studies gave prime importance to the pain experience, rather than to other neurological manifestations such as hypoesthesia, myotomal weakness, or alterations in tendon reflexes. Diagnosing neuropathic pain is essential as neuropathic pain tends to lower the quality of life to a greater degree compared to nociceptive pain. ${ }^{[6]}$ Hence, the importance of the DN4 as a validated diagnostic neuropathic pain questionnaire to differentiate between sciatic pain with a distinct neuropathic pain component from sciatica with a nociceptive pain component only. This offers standardization, hence facilitating the comparison of results between subjects and any future studies. Another strength of this study was that the population was a specific patient subgroup with chronic LBP, with or without radicular neuropathic leg pain. Nonetheless, this poses challenges on the generalizability of the results to acute, subacute LBP, and to other neuropathic pain conditions and may be considered as a limitation of this study.

A limitation was the significant element of recall bias when current smokers in both chronic pain and control groups were asked when they had started smoking, which most could not recall exactly. More than $75 \%$ of the subjects in both groups reported a history of at least 15 years of smoking, with fluctuations in the number of cigarettes smoked daily. Despite the dose-response analysis carried out in this paper, 
the temporal aspects of daily cigarette consumption could influence the symptomatology and possibly affect the conclusion of this study. Selection bias could have arisen since the patients were referred from the main general hospital to the physiotherapy outpatients department. The patient cohort was mixed in nature with the majority of the participants having already undergone unsuccessful medical treatment and hence represents a more refractory cohort of chronic LBP patients, while for others, it was their first attempt at managing their chronic LBP. The subjects were not randomized, but it was a consecutive sample of eligible subjects. However, such selection bias was beyond the authors' control. Nonetheless, the chronic pain group was representative of the principal investigator's yearly clinical caseload.

Future research, using longitudinal studies, could investigate after how many months or years of smoking cessation, the heightened risk of developing chronic LBP and neuropathic radicular leg pain decreases. The use of validated neuropathic pain diagnostic tools is encouraged to facilitate standardization and study reproducibility. Besides, considering the significant difference in the DN4 Interview subscore between current smokers and non-smokers $(p=0.000)$, it would be interesting for future research to asses if specific psychological constructs mediate the association between neuropathic pain dysesthesias specifically in current smokers, for example, anxiety, depression, stress, pain self-efficacy, pain coping, or catastrophizing, through the use of appropriate measures, which due to the time constraints of the clinical assessment within the current study was not doable. This can shed light on the psychobiology underlying neuropathic pain in smokers.

\section{Conclusion}

This study shows that current smokers and a higher nicotine dependency were both independently associated with a higher odds ratio for the presence of chronic LBP, lumbar related leg pain, and chronic radicular neuropathic leg pain. This may have implications on treatment effect and patient outcomes.

Ethical approval: All procedures performed in studies involving human participants were in accordance with the ethical standards of the institutional research committee and with the 1975 Helsinki declaration and its later amendments or comparable ethical standards.
Conflict-of-interest issues regarding the authorship or article: None declared.

Written informed consent was obtained from all individual participants prior to enrolment in the study.

Funding: Emanuel Schembri received funding from the Endeavour Scholarship Scheme (Malta). Scholarships are part-financed by the European Union - European Social Fund (ESF) - Operational Programme II - Cohesion Policy 2014-2020 "Investing in human capital to create more opportunities and promote the well-being of society."

Peer-rewiew: Externally peer-reviewed.

\section{References}

1. Vos T, Abajobir A, Abate K, Abbafati C, Abbas K, Abd-Allah $F$, et al. Global, regional, and national incidence, prevalence, and years lived with disability for 328 diseases and injuries for 195 countries, 1990-2016: A systematic analysis for the global burden of disease study 2016. Lancet 2017;390(10100):1211-59.

2. Krismer M, van Tulder M. Low back pain (non-specific). Best Pract Res Clin Rheumatol 2007;21(1):77-91. [CrossRef]

3. Kendell M, Beales D, O'Sullivan P, Rabey M, Hill J, Smith A. The predictive ability of the STarT Back Tool was limited in people with chronic low back pain: A prospective cohort study. J Physiother 2018;64(2):107-13. [CrossRef]

4. Colloca L, Ludman T, Bouhassira D, Baron R, Dickenson A, Yarnitsky D, et al. Neuropathic pain. Nat Rev Dis Primers 2017;3(1):17002. [CrossRef]

5. Jensen $T$, Baron R, Haanpää $M$, Kalso $E$, Loeser J, Rice $A$, et al. A new definition of neuropathic pain. Pain 2011;152(10):2204-5. [CrossRef]

6. Euro U, Knekt P, Rissanen H, Aromaa A, Karppinen J, Heliövaara M. Risk factors for sciatica leading to hospitalization. Eur Spine J 2017;27(7):1501-8. [CrossRef]

7. Schembri E. Are opioids effective in relieving neuropathic pain? SN Compr Clin Med 2018;1(1):30-46. [CrossRef]

8. Ferreira P, Beckenkamp P, Maher C, Hopper J, Ferreira M. Nature or nurture in low back pain? Results of a systematic review of studies based on twin samples. Eur J Pain 2013;17(7):957-71. [CrossRef]

9. Parreira $P$, Maher $C$, Steffens D, Hancock M, Ferreira M. Risk factors for low back pain and sciatica: An umbrella review. Spine J 2018;18(9):1715-21. [CrossRef]

10. Shiri R, Karppinen J, Leino-Arjas P, Solovieva S, Varonen $\mathrm{H}$, Kalso $\mathrm{E}$, et al. Cardiovascular and lifestyle risk factors in lumbar radicular pain or clinically defined sciatica: A systematic review. Eur Spine J 2007;16(12):2043-54. [CrossRef]

11. Cook C, Taylor J, Wright A, Milosavljevic S, Goode A, Whitford M. Risk factors for first time incidence sciatica: A systematic review. Physiother Res Int 2014;19(2):65-78. [CrossRef]

12. Shiri R, Falah-Hassani K. The effect of smoking on the risk of sciatica: A meta-analysis. Am J Med 2016;129(1):6473.e20. [CrossRef] 
13. Pourmemari M, Viikari-Juntura E, Shiri R. Smoking and carpal tunnel syndrome: A meta-analysis. Muscle Nerve 2013;49(3):345-50. [CrossRef]

14. Clair C, Cohen M, Eichler F, Selby K, Rigotti N. The effect of cigarette smoking on diabetic peripheral neuropathy: A systematic review and meta-analysis. J Gen Intern Med 2015;30(8):1193-203. [CrossRef]

15. Frost $P$, Johnsen B, Fuglsang-Frederiksen A, Svendsen $S$. Lifestyle risk factors for ulnar neuropathy and ulnar neuropathy-like symptoms. Muscle Nerve 2013;48(4):50715. [CrossRef]

16. Suzuki T, Iwamoto T, Ochi K, Mito K, Nakamura T, Suzuki $\mathrm{K}$, et al. Cigarette smoking is associated with cubital tunnel syndrome. Muscle Nerve 2016;54(6):1136-8. [CrossRef]

17. Shi Y, Weingarten T, Mantilla C, Hooten W, Warner D. Smoking and pain. Anesthesiology 2010;113(4):977-92.

18. Khan J, Hah J, Mackey S. Effects of smoking on patients with chronic pain. Pain 2019;160(10):2374-9. [CrossRef]

19. Hill J, Dunn K, Lewis M, Mullis R, Main C, Foster N, et al. A primary care back pain screening tool: Identifying patient subgroups for initial treatment. Arthritis Rheum 2008;59(5):632-41. [CrossRef]

20. Çelik S, Can H, Sözmen M, Şengezer T, Kaplan Y, Utlu G, et al. The evaluation of the neuropathic pain in the smokers. Ağrı 2017;29:122-6. [CrossRef]

21. Nicholas M, Vlaeyen J, Rief W, Barke A, Aziz Q, Benoliel R, et al. The IASP classification of chronic pain for ICD-11. Pain 2019;160(1):28-37. [CrossRef]

22. Lewis R, Williams N, Matar H, Din N, Fitzsimmons D, Phillips $C$, et al. The clinical effectiveness and cost-effectiveness of management strategies for sciatica: Systematic review and economic model. Health Technol Assess 2011;15(39):1-578. [CrossRef]

23. Vandenbroucke J, von Elm E, Altman D, Gøtzsche P, Mulrow $C$, Pocock $S$, et al. Strengthening the reporting of observational studies in epidemiology (STROBE): Explanation and elaboration. Int J Surg 2014;12(12):1500-24.

24. Schembri E, Massalha V, Camilleri L, Casha M. The Maltese Version of the DN4 Questionnaire: Initial validation to assess neuropathic pain in patients with chronic spinal or spinal-radicular pain. Malta Medical School Gazette; 2019. p. 37-52.

25. Dworkin R, Turk D, Farrar J, Haythornthwaite J, Jensen $\mathrm{M}$, Katz $\mathrm{N}$, et al. Core outcome measures for chronic pain clinical trials: IMMPACT recommendations. Pain 2005;113(1):9-19.

26. Hasvik E, Haugen A, Gjerstad J, Grøvle L. Assessing neuropathic pain in patients with low back-related leg pain: Comparing the painDETECT Questionnaire with the 2016 NeuPSIG grading system. Eur J Pain 2018;22(6):1160-9.

27. Bouhassira D, Attal N, Alchaar $H$, Boureau F, Brochet $B$, Bruxelle J, et al. Comparison of pain syndromes associated with nervous or somatic lesions and development of a new neuropathic pain diagnostic questionnaire (DN4). Pain 2005;114(1):29-36. [CrossRef]
28. Bisaga W, Dorazil M, Dobrogowski J, Wordliczek1 J. A comparison of the usefulness of selected neuropathic pain scales in patients with chronic pain syndromes: $A$ short communication. Adv Pall Med 2010;9(4):117-21.

29. Mathieson S. Neuropathic pain screening questionnaires have limited measurement properties. A systematic review. J Clin Epidemiol 2016;5(4):957-66.

30. Attal N, Perrot S, Fermanian J, Bouhassira D. The neuropathic components of chronic low back pain: A prospective multicenter study using the DN4 questionnaire. J Pain 2011;12(10):1080-7. [CrossRef]

31. Fagerstrom K, Schneider N. Measuring nicotine dependence: A review of the Fagerstrom tolerance questionnaire. J Behav Med 1989;12(2):159-82. [CrossRef]

32. Heatherton T, Kozlowski L, Frecker R, Fagerstrom K. The Fagerstrom test for nicotine dependence: A revision of the Fagerstrom tolerance questionnaire. $\mathrm{Br} J$ Addict 1991;86(9):1119-27. [CrossRef]

33. Beneciuk J, Robinson M, George S. Subgrouping for patients with low back pain: A multidimensional approach incorporating cluster analysis and the STarT back screening tool. J Pain 2015;16(1):19-30. [CrossRef]

34. Toh I, Chong HC, Suet-Ching Liaw J, Pua YH. Evaluation of the STarT back screening tool for prediction of low back pain intensity in an outpatient physical therapy setting. J Orthop Sports Phys Ther 2017;47(4):261-7. [CrossRef]

35. Pagé I, Abboud J, O'Shaughnessy J, Laurencelle L, Descarreaux M. Chronic low back pain clinical outcomes present higher associations with the STarT Back Screening Tool than with physiologic measures: A 12-month cohort study. BMC Musculoskelet Disord 2015;16(1):201.

36. Beneciuk J, Bishop M, Fritz J, Robinson M, Asal N, Nisenzon $A$, et al. The STarT back screening tool and individual psychological measures: evaluation of prognostic capabilities for low back pain clinical outcomes in outpatient physical therapy settings. Phys Ther 2013;93(3):321-33.

37. Beneciuk J, Fritz J, George S. The STarT back screening tool for prediction of 6-month clinical outcomes: Relevance of change patterns in outpatient physical therapy settings. J Orthop Sports Phys Ther 2014;44(9):656-64.

38. Shemory S, Pfefferle K, Gradisar I. Modifiable risk factors in patients with low back pain. Orthopedics 2016;39(3):e413-6. [CrossRef]

39. Shaw W, Means-Christensen A, Slater M, Webster J, Patterson T, Grant I, et al. Psychiatric disorders and risk of transition to chronicity in men with first onset low back pain. Pain Med 2010;11(9):1391-400. [CrossRef]

40. Zvolensky M, McMillan K, Gonzalez A, Asmundson G. Chronic pain and cigarette smoking and nicotine dependence among a representative sample of adults. Nicotine Tob Res 2009;11(12):1407-14. [CrossRef]

41. Shiri R, Karppinen J, Leino-Arjas P, Solovieva S, ViikariJuntura $E$. The association between smoking and low back pain: A meta-analysis. Am J Med 2010;123(1):87-7. e7-35. [CrossRef] 
42. Green B, Johnson C, Haldeman S, Griffith E, Clay M, Kane $E$, et al. A scoping review of biopsychosocial risk factors and co-morbidities for common spinal disorders. PLoS One 2018;13(6):e0197987. [CrossRef]

43. Scaia V, Baxter D, Cook C. The pain provocation-based straight leg raise test for diagnosis of lumbar disc hernia- tion, lumbar radiculopathy, and/or sciatica: A systematic review of clinical utility. J Back Musculoskelet Rehabil 2012;25(4):215-23. [CrossRef]

44. Finnerup $N$, Haroutounian S, Kamerman $P$, Baron $R$, Bennett D, Bouhassira D, et al. Neuropathic pain. Pain 2016;157(8):1599-606. [CrossRef] 